Research Article

\title{
A Simple Method to Control the Growth of Copper Oxide Nanowires for Solar Cells and Catalytic Applications
}

\author{
L. Nkhaili $(\mathbb{D}$, A. Narjis, A. Agdad, A. Tchenka, A. El Kissani, A. Outzourhit, and A. Oueriagli \\ Nanomaterials for Energy and Environment Laboratory, Physics Department, Faculty of Sciences Semlalia, \\ Cadi Ayyad University, P.O. Box 2390, Marrakech 40000, Morocco \\ Correspondence should be addressed to L. Nkhaili; lahcen.com@hotmail.fr
}

Received 14 April 2020; Revised 23 July 2020; Accepted 1 September 2020; Published 12 September 2020

Academic Editor: Charles Rosenblatt

Copyright $\odot 2020$ L. Nkhaili et al. This is an open access article distributed under the Creative Commons Attribution License, which permits unrestricted use, distribution, and reproduction in any medium, provided the original work is properly cited.

Copper oxide nanowires ( $\mathrm{CuO}$ NWs) were synthesized by thermally oxidizing copper foils at various heating rates. It has been shown that both monoclinic $\mathrm{CuO}$ and cubic $\mathrm{Cu}_{2} \mathrm{O}$ phases were grown on the copper surface with NW diameters of almost $200 \mathrm{~nm}$ for all samples. While NWs were shown to be dense for low heating rates, they end up being broken for quick heating. The underlying growth mechanism was described basing on a detailed comprehensive study, and the effect of the heating rate was explained by considering the thermal shock effect and in-plane tensile stresses on curved surfaces. This study contributes to the research for suitable methods for the use of recyclable metals in technological applications. In particular, copper oxide NWs were deposited, for the first time, on FTO/glass substrates, and the optical characterization revealed that this method is a promising way to improve the surface contact for solar cells and catalytic applications.

\section{Introduction}

Cupric oxide $(\mathrm{CuO})$ and cuprous oxide $\left(\mathrm{Cu}_{2} \mathrm{O}\right)$ are p-type semiconductors with a band gap of 1.2 and $2 \mathrm{eV}$, respectively. Their electrical and optical properties make them very useful as interesting constituents in photovoltaic applications [1-3], gas and liquid sensors $[4,5]$, electron stable source in optoelectronic devices [6,7], and organic catalysts $[8,9]$.

$\mathrm{CuO}$ nanowires (NWs) have been intensively synthesized and studied over the course of the last few years [10-15]. Their large surface area makes them very interesting for the abovementioned applications. In fact, the large surface contact in a $p-n$ junction leads to a significant generation of excitons, which enhances the photocurrent in the solar cell and partially overcomes the phenomenon of recombination due to the limited scattering length of electron-hole pairs near the depletion region. Similarly, the gas sensing gets favored on NWs because of the large surface area $[16,17]$. The sharp tips of the $\mathrm{CuO}$ NWs lead to a large electrical field at its boundaries. This justifies its uses as an electron source in optoelectronic devices.
$\mathrm{CuO}$ NWs can be synthesized by several methods [18], including chemical routes [19-22], direct plasma oxidation [23, 24], and thermal oxidation of copper substrates $[10-15,25]$. The latter is a pragmatic method.

\section{Thermal Oxidation of Copper Substrates}

Heating directly leads to synthesize copper oxide NWs on the surface of a copper substrate, either as a foil [10-15], a wire [10], a grid [10], a thin film [25], or nanoparticles [26]. This method is carried out at high temperature, typically between $400^{\circ} \mathrm{C}$ and $700^{\circ} \mathrm{C}$, in air or in other static or flowing atmosphere (pure $\mathrm{O}_{2}$, a mixture of $\mathrm{O}_{2}$ and Ar gases, and so on).

The pioneer synthesis of $\mathrm{CuO}$ NWs by the thermal oxidation method was performed by Jiang et al. on different substrates during 4 hours [10]. The observed length was up to $15 \mu \mathrm{m}$, and the NW diameter was found to be 100,50 , and $30 \mathrm{~nm}$ for the heating temperature of 400,500 , and $600^{\circ} \mathrm{C}$, respectively. Later, $\mathrm{Xu}$ et al. also synthesized $\mathrm{CuO}$ NWs by heating copper foils [11]. Their results concerning the length and the diameters were comparable to that found by Jiang 
et al. [10] with remarkably high NWs density for the heating temperature of 500 and $600^{\circ} \mathrm{C}$.

The morphological properties of $\mathrm{CuO}$ NWs (diameter, length, density) have been shown to depend on the heating temperature [27, 28], the treatment time [28], and the substrate nature [10]. However, to the best of our knowledge, no study has been devoted to the heating rate effect.

In this paper, $\mathrm{CuO} \mathrm{NWs}$ have been synthesized by thermal oxidation at $550^{\circ} \mathrm{C}$ for 4 hours in air. The effect of the heating rate was studied down to $1^{\circ} \mathrm{C} / \mathrm{min}$. Physical explanations are given based on the underlying growth mechanism. As application, $\mathrm{CuO}$ NWs were deposited on a copper thin film for using in solar cells and catalytic applications.

\section{Experimental}

Each recyclable copper foil (intended for public uses) is with a thickness of $0.3 \mathrm{~mm}$. It was ultrasonically cleaned for $10 \mathrm{~min}$ in ethanol, $10 \mathrm{~min}$ in acetone, and $10 \mathrm{~min}$ in distilled water and, then, heated in air using a Nabertherm box furnace for 4 hours. Copper oxide NWs could be grown by heating at a temperature between 400 and $700^{\circ} \mathrm{C}[10,11]$. In the present investigation, all substrates were heated at $550^{\circ} \mathrm{C}$. However, the heating rate took various values.

As applications, $\mathrm{CuO}$ NWs were deposited on a copper thin film. The latter was prepared by the electrodeposition method on an FTO-coated glass substrate using standard three electrodes. We used an FTO substrate of $0.8 \times 1.5 \mathrm{~cm}$ as a working electrode (WE), a platinum mesh was used as a counter electrode (CE), and a saturated calomel electrode (SCE) as a reference electrode. The thin films were deposited from an aqueous solution containing $0.4 \mathrm{M}$ copper sulphate $\left(\mathrm{CuSO}_{4} \cdot 5 \mathrm{H}_{2} \mathrm{O}\right)$ and $3 \mathrm{M}$ lactic acid. The $\mathrm{pH}$ of the bath solution was adjusted to 5 by sodium hydroxide $(\mathrm{NaOH})$ maintained at $60^{\circ} \mathrm{C}$, and $\mathrm{Cu}$ films were deposited within the potentiostatic mode by imposing a voltage of $V=0.4 \mathrm{~V} / \mathrm{SCE}$ during $800 \mathrm{~s}$. The thickness of the $\mathrm{Cu}$ thin film is $0.6 \mu \mathrm{m}$ measured using the Michelson interferometer. NWs grown on $\mathrm{Cu}$ films on FTO were synthesized by thermal oxidation at $500^{\circ} \mathrm{C}$ for 4 hours in air at a step of $2^{\circ} \mathrm{C} / \mathrm{min}$.

X-Ray Diffractions (DRX) were performed using a Bruker D8 Advanced Diffractometer. Scanning electron microscopy and energy dispersive X-ray microanalysis were carried out on a VEGA3 TESCAN. Optical transmittance data were taken using a Shimadzu UV-PC spectrophotometer in the $200-3200 \mathrm{~nm}$ range.

\section{Results and Discussion}

For the heating rates of $1,2,5$, and $10^{\circ} \mathrm{C} / \mathrm{min}$, representative SEM images of the obtained samples are displayed in Figure 1 . All surfaces were covered by NWs with comparable diameter, which is found to be almost $200 \mathrm{~nm}$. Also, we noticed that the NWs' density is stable and, then, decreases by increasing the heating rate (Table 1). However, some regions exhibit less dense NWs islands. Figure 2-left shows this observation for the heating rate of $5^{\circ} \mathrm{C} / \mathrm{min}$ using another scale. The uncovered surface was found to increase with increasing heating rate. Thus, the formation of dense
NWs needs to use a slow heating. To further confirm this assumption, another copper substrate was heated at the rate of $15^{\circ} \mathrm{C} / \mathrm{min}$. The SEM image of the so obtained sample is shown in Figure 2-right. By quick heating, the NWs were destructed. In fact, some of them were displayed with a noteworthy fragility. To explain the effect of the heating rate on the $\mathrm{CuO}$ NWs growth, a comprehensive study on the underlying mechanism was required.

Two mechanisms have been commonly described to explain the growth of NWs in the gas phase: Vapor-LiquidSolid (VLS) [29] and Vapor-Solid (VS) [30]. The VLS is excluded because no NW was terminated by spherical particle, and the VS mechanism is also excluded for two reasons: First, no $\mathrm{CuO}$ was observed to depose around the sample, and second, the growth of $\mathrm{CuO}$ NWs occurs at a temperature much lower than the melting points $\left(1232^{\circ} \mathrm{C}\right.$ for $\mathrm{Cu}_{2} \mathrm{O}$ and $1326^{\circ} \mathrm{C}$ for $\mathrm{CuO}$ ). In a previous study, the vapor pressure of $\mathrm{CuO}$ has been observed to be just $1.15 \times 10^{-4} \mathrm{~mm} \cdot \mathrm{Hg}$ at $800^{\circ} \mathrm{C}[31,32]$.

The most probable mechanism is the stress-induced diffusion. This process has been previously supported by experimental observations $[33,34]$ and explained by Li et al. [35] as follows: (a) formation of monoclinic crystal nuclei with a pointed rhombic prism shape and (b) growth of $\mathrm{CuO}$ NWs on a continuous $\mathrm{CuO}$ scale because of the short-circuit diffusion of copper ions trough grain surfaces. This explanation was also supported by the experimental data, and it used the theory of crystallography (TOC) [36]. However, the starting reactive was $\mathrm{Cu}_{2} \mathrm{O}$ instead of copper. In the present case, the stress-induced diffusion of $\mathrm{Cu}^{2+}$ ions is believed to be valid, including the thermal and compressive stresses. The growth of $\mathrm{CuO}$ NWs on a copper substrate can be described by considering the following process. At the beginning, copper is oxidized following the reaction

$$
2 \mathrm{Cu}+\frac{1}{2} \mathrm{O}_{2} \rightleftarrows \mathrm{Cu}_{2} \mathrm{O}
$$

During the next step, $\mathrm{Cu}_{2} \mathrm{O}$ served as a precursor to $\mathrm{CuO}$. Indeed, the chemisorbed oxygen attracts an electron from the $\mathrm{Cu}_{2} \mathrm{O}$ lattice, and then, fully ionized oxygen reacts with a $\mathrm{Cu}^{2+}$ ion according the reaction:

$$
\frac{1}{2} \mathrm{O}_{2} \rightleftarrows \mathrm{CuO}+2 \mathrm{~h}^{+}+\left(\mathrm{V}_{\mathrm{Cu}}\right)^{2-}
$$

The emerging holes $\left(2 \mathrm{~h}^{+}\right)$and copper ion vacancy (having a positive charge of $+2 \mathrm{e}$ and a negative charge of $-2 \mathrm{e}$, respectively) are attracted by a molecular $\mathrm{Cu}_{2} \mathrm{O}$ to form a $\mathrm{CuO}$ molecule as follows:

$$
\mathrm{Cu}_{2} \mathrm{O}+2 \mathrm{~h}^{+}+\left(\mathrm{V}_{\mathrm{Cu}}\right)^{2-} \rightleftarrows \mathrm{CuO}
$$

We believe that both the $\mathrm{Cu}_{2} \mathrm{O}$ cubic lattice and $\mathrm{CuO}$ monoclinic lattice coexist in the thin film. This was confirmed by performing the XRD displayed in Figure 3. The reaction (3) is known to be very slow. However, it results in a significant effect on the final composition and shape of the oxide. Indeed, the precipitation of monoclinic crystal nuclei exhibits pointed ends in the critical nucleus according to the TOC [36]. As the electric field is strong at the points, charges 


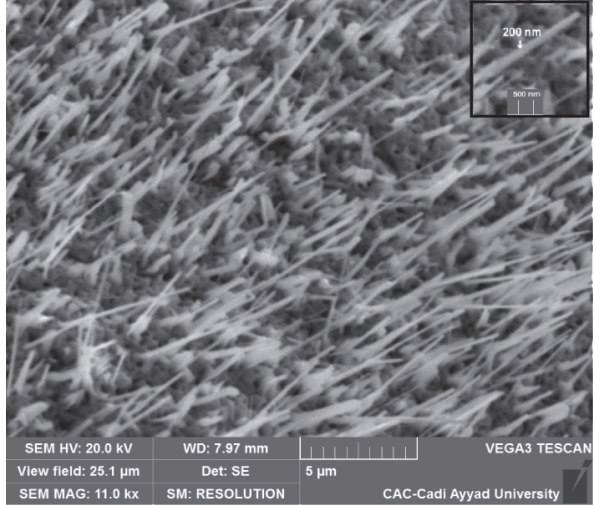

(a)

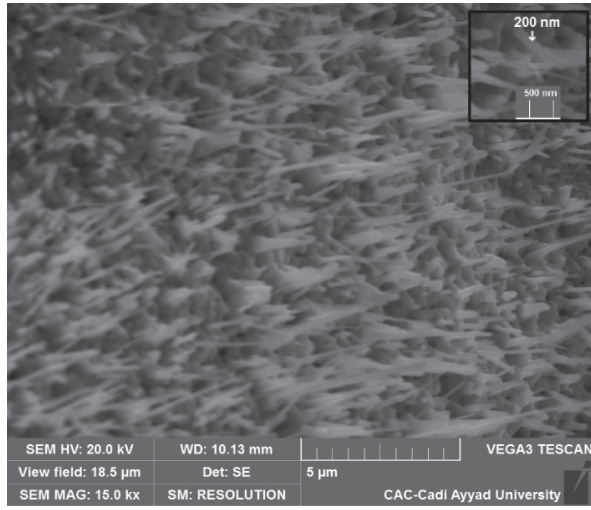

(c)

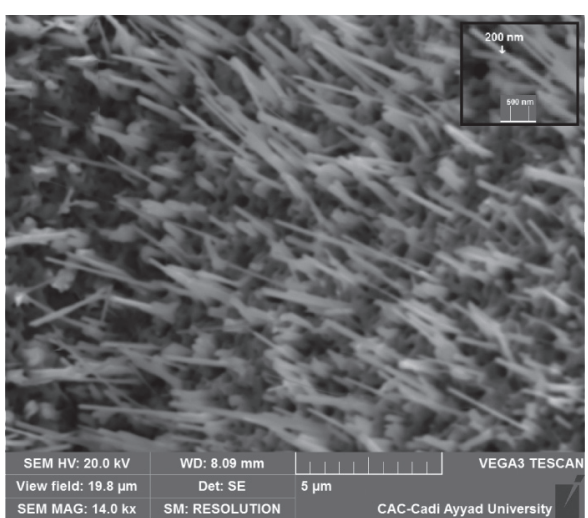

(b)

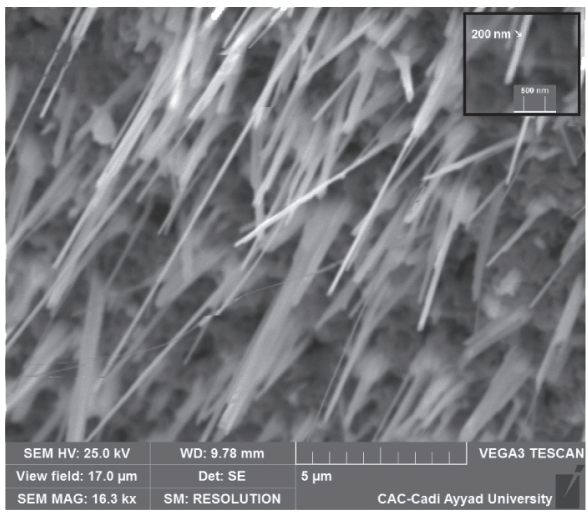

(d)

FIgURE 1: SEM images for $\mathrm{CuO}$ NWs obtained by thermal oxidation of copper foils at $550^{\circ} \mathrm{C}$ for $4 \mathrm{~h}$ The heating rates are (a) $1^{\circ} \mathrm{C} / \mathrm{min}$; (b) $2^{\circ} \mathrm{C} / \mathrm{min}$; (c) $5^{\circ} \mathrm{C} / \mathrm{min}$; and (d) $10^{\circ} \mathrm{C} / \mathrm{min}$. While the diameter is almost the same in all samples, the $\mathrm{NW}$ density slightly decreases with increasing the heating rate.

TABLE 1: NWs density estimated by the SEM images and crystallite size calculated using the Scherrer equation for various heating rates.

\begin{tabular}{|c|c|c|c|}
\hline \multirow{2}{*}{ Heating rate $\left({ }^{\circ} \mathrm{C} / \mathrm{min}\right)$} & \multirow{2}{*}{ NWs density $\left(\times 10^{8} \mathrm{~cm}^{-2}\right)$} & \multicolumn{2}{|c|}{ Crystallite size $(\mathrm{nm})$} \\
\hline & & $\mathrm{CuO}$ & $\mathrm{Cu}_{2} \mathrm{O}$ \\
\hline 1 & 2.8 & 24.9 & 20 \\
\hline 2 & 2.2 & 25.9 & 24.8 \\
\hline 5 & 2.9 & 25.9 & 24.8 \\
\hline 10 & 1.1 & 24.8 & 23 \\
\hline
\end{tabular}
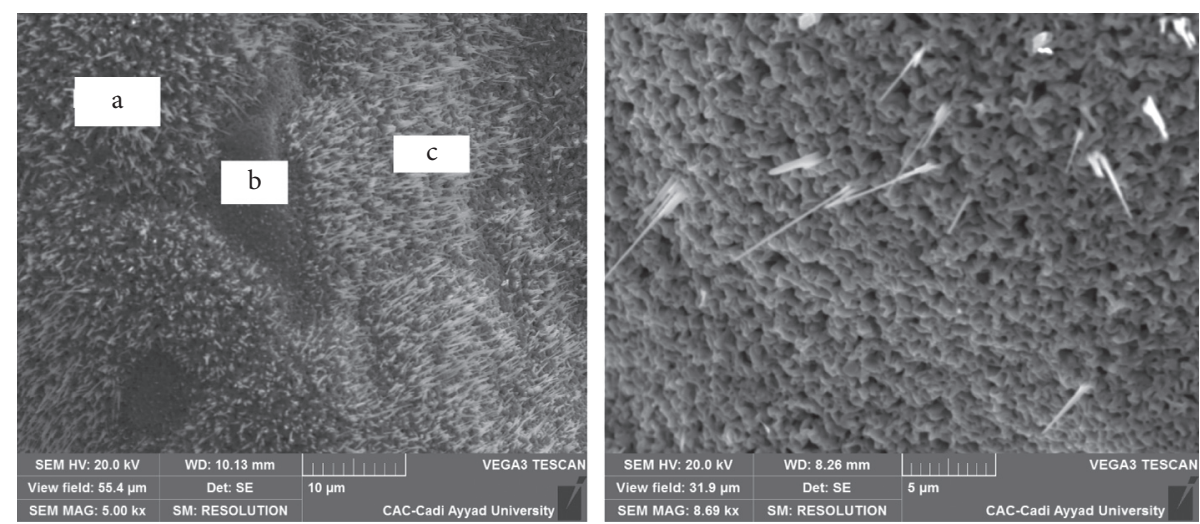

Figure 2: SEM images for the sample synthesized at $5^{\circ} \mathrm{C} / \mathrm{min}$ (left)- a: dilute island; b: NWs finished being broken; and c: dense island; the sample synthesized at $15^{\circ} \mathrm{C} / \mathrm{min}$ (right). The lack of homogeneity and the NWs breaking are caused by the thermal shock-induced in-plane tensile stresses. 


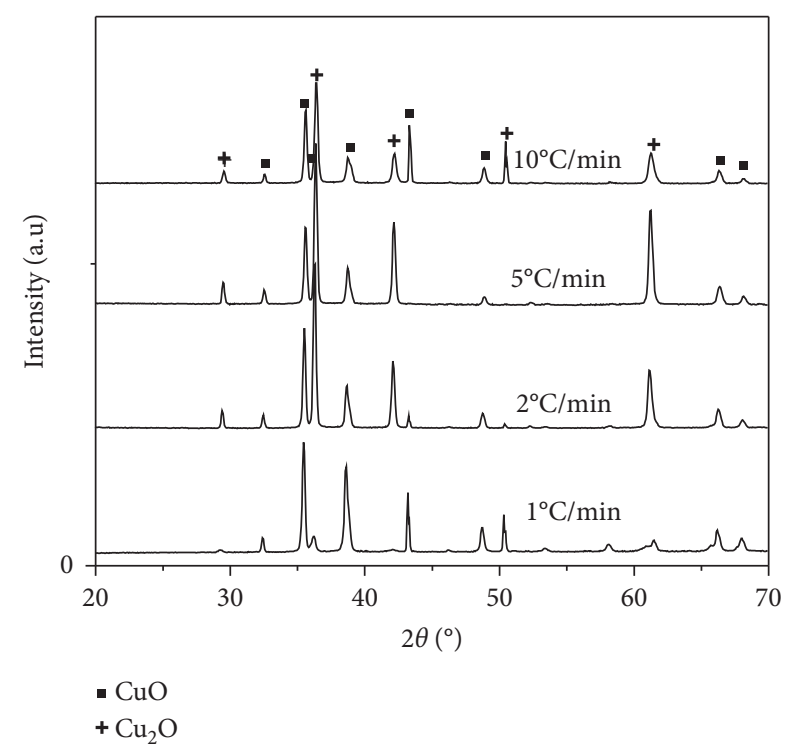

FIGURE 3: XRD pattern of the four samples obtained by the heating rates $1,2,5$, and $10^{\circ} \mathrm{C} / \mathrm{min}$. Both copper oxides have been observed to appear by thermal oxidation of copper foils at $550^{\circ} \mathrm{C}$ for $4 \mathrm{~h}$.

are easily attracted to form an accumulating $\mathrm{CuO}$ layers on the NW tip.

It is worth noticing that the amount of the $\mathrm{Cu}_{2} \mathrm{O}$ phase decreases by decreasing the heating rate since the reaction 3 took its enough time to take place. Indeed, the corresponding peaks in the XRD pattern are not as intense as those of the $\mathrm{CuO}$ phase for the heating rate of $1^{\circ} \mathrm{C} / \mathrm{min}$. On the other hand, the crystallite sizes calculated using the Scherrer equation did not exhibit a significant change by varying the heating rate (Table 1 ).

Given the abovementioned explanations, each NW was expected to be formed of monoclinic $\mathrm{CuO}$ lattices and its nucleation site may contain $\mathrm{Cu}_{2} \mathrm{O}$ cubic lattices. In fact, the EDX microanalysis performed on the sample synthesized at $10^{\circ} \mathrm{C} / \mathrm{min}$ showed that copper and oxygen percentages are almost equal on the NW (spot 1 in Figure 4) indicating that the NW is formed by the CuO lattice, whereas on the NW base, the percentage of copper was shown to be more than two times greater than that of oxygen (spot 2 in Figure 4), which may be due to the existence of $\mathrm{CuO}, \mathrm{Cu}_{2} \mathrm{O}$, and $\mathrm{Cu}$ lattices on the NW base.

To obtain NWs with high density, intense outward diffusions are required. Therefore, continuous supply of copper ions through grain boundaries has to be ensured. The nucleation of NWs islands is obtained when the underlying layer is enough dense to overcome the nucleation barrier. By considering heterogeneous nucleation of an oxide island on the metal surface, this barrier is written as [37]

$$
E_{N}=f(\theta) \sigma^{3} \frac{1}{\left(\Delta G_{s}+\Delta G_{V}\right)^{2}}
$$

where $f(\theta)$ is a geometric function. $\sigma$ is the surface energy of the oxide, $\Delta G_{s}$ is the energy due to the lattice mismatch between the copper and its oxide, and $\Delta G_{V}$ is the free energy of the oxidation reaction. The number of nucleation sites increases with decreasing $E_{N}$. On the other hand, $\Delta G_{V}<0$, $\Delta G_{s}>0$, and $\left|\Delta G_{s}\right|<\left|\Delta G_{V}\right|$, so that the decrease of $\Delta G_{s}$ results in increasing the denominator of equation (4). This results in decreasing $E_{N}$. Hence, one method to enhance the NWs density is to reduce $\Delta G_{s}$. This can be achieved by exerting bending stresses on the copper surface [38]. However, some regions of the treated samples were naturally bent (in the initial form or by thermal shock during heating). This explains the appearance of dense and dilute NWs islands. The underlying mechanism is shown in Figure 5. By heating a bent substrate, the in-plane tensile stresses result in the reduction of the lattice mismatch between the copper and the oxide lattices ( $\Delta G_{s}$ decreases) and the NWs density is expected to increase. In our case, however, some NWs are broken because of the small base, which reduces the NWs density. It is worth noticing that the region $b$ in Figure 5 shows compressive stresses. However, this does not result in any change in the NWs density as compared with the unbent region [38].

In the present study, some regions were naturally bent and the in-plane tensile stresses make them covered by dense NWs. On the contrary, NWs are less dense on the unbent regions. For the sample heated at a rate of $15^{\circ} \mathrm{C} / \mathrm{min}$, quick heating enhances curvature of some bent regions. The inplane tensile stresses result in small oxide grain size and, therefore, lead to form small nucleation sites, NWs on which end up being broken. Hence, the grain size was expected to be small for slow heating. To confirm this assumption, NWs formed by the heating at $2^{\circ} \mathrm{C} / \mathrm{min}$ were cleaned by acetone to show its nucleation sites by the SEM (Figure 6(a)). Compared with the nucleation sites of the sample synthesized at $15^{\circ} \mathrm{C} / \mathrm{min}$ (Figure 6(b)), nucleation sites at slow heating are more compact with lower porosity.

\section{Application: Synthesis of CuO NWs on FTO/ Glass Substrates}

As application, we deposited $\mathrm{CuO}$ NWs on copper thin films deposited by the electrodeposition method on an FTOcoated glass substrate. The underlying aim is to obtain transparent films for using in solar cells and catalytic applications. In fact, by obtaining NWs array, the surface contact at the solar cell junction or between the reactors and the catalyst (thin film) increases, and thus, the efficiency is expected to increase in both cases.

As shown in Figure 7(a), the obtained phase is for copper oxide. On the other hand, the SEM images (Figure 7(c)) show that $\mathrm{CuO}$ NWs were obtained on the deposited copper film. The EDX analysis (Figure 7(d)) revealed that the oxygen percentage is $55.4 \%$, while that of copper is $41.8 \%$, which corresponds to the $\mathrm{CuO}$ compound. The transmission spectra of the films are depicted in Figure 7(b). Average transmittance in the visible spectrum was lower than $1 \%$ with the band gap $(\mathrm{Eg})$ values calculated from the extrapolation of linear line portion of the plot of $(\alpha \mathrm{h} v)^{2}$ versus $(\mathrm{h} v)$ as shown in the Figure 7(b). The band gap value of $\mathrm{CuO}$ nanowires was found to be about $1.21 \mathrm{eV}$. The absorption coefficient $(\alpha)$ is calculated using the following relation: 

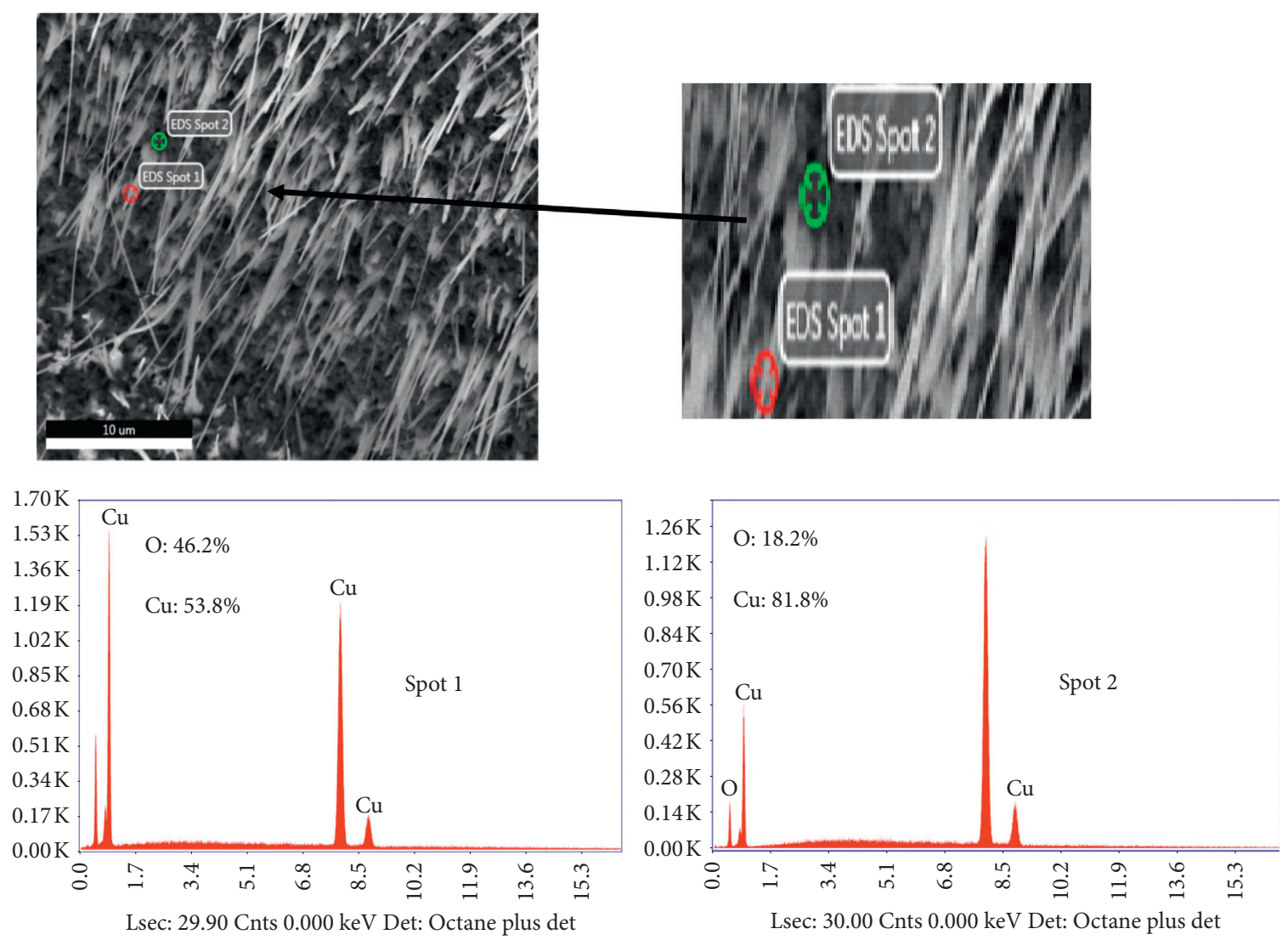

FIgURE 4: EDX analysis for the sample obtained by heating at $10^{\circ} \mathrm{C} / \mathrm{min}$. Spot 1: the NW contains the CuO lattice. Spot 2: the nucleation site base may contain $\mathrm{CuO}, \mathrm{Cu}_{2} \mathrm{O}$, and $\mathrm{Cu}$ lattices.

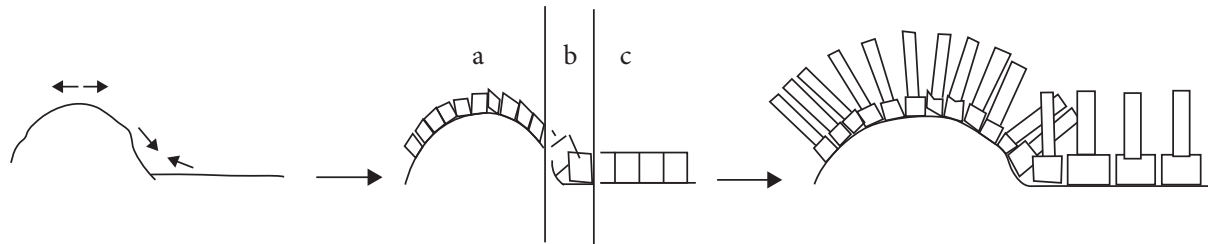

Figure 5: Effect of the bending stresses on the NWs density. Arrows indicate the corresponding stresses. In-plan tensile stresses on the top surface of the bent region (region a) result in the growth of dense NWs. On the contrary, the unbent region (region c) is covered by less dense NWs because of the grain size.

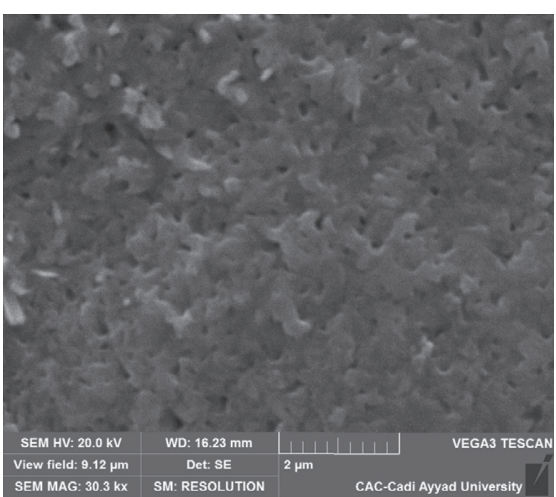

(a)

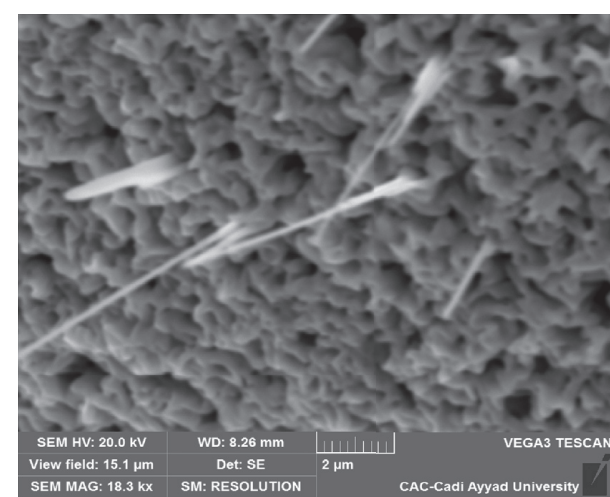

(b)

Figure 6: SEM image of nucleation sites for the samples synthesized at (a) $2^{\circ} \mathrm{C} / \mathrm{min}$ after cleaning NWs by acetone and (b) $15^{\circ} \mathrm{C} / \mathrm{min}$. The slow heating results in more compact nucleation sites with low porosity. 


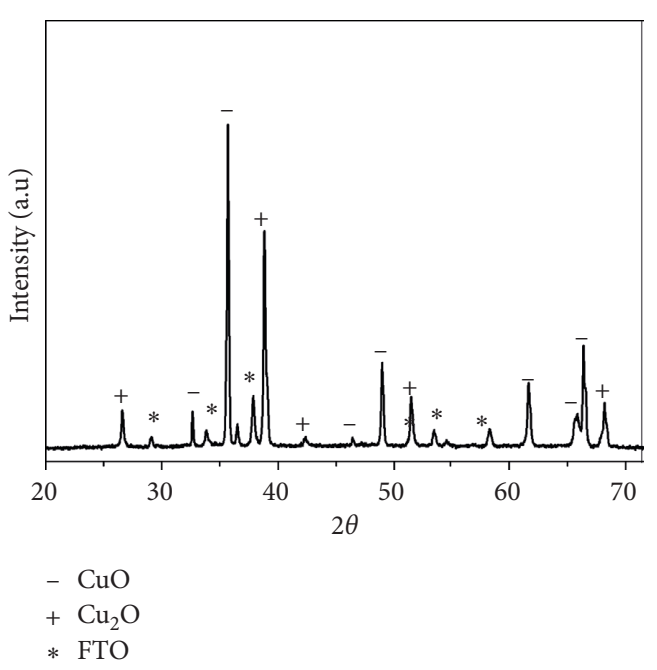

(a)
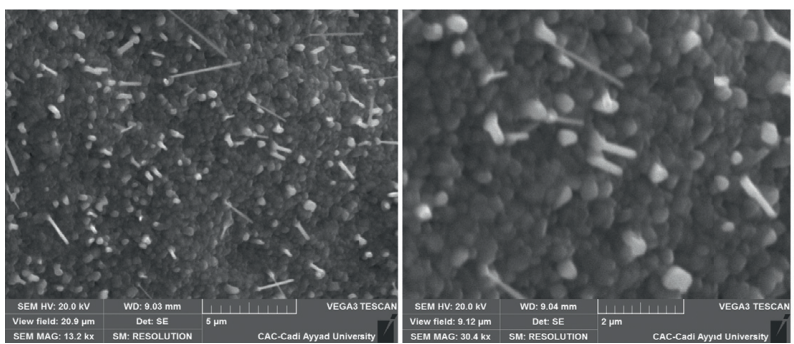

(c)

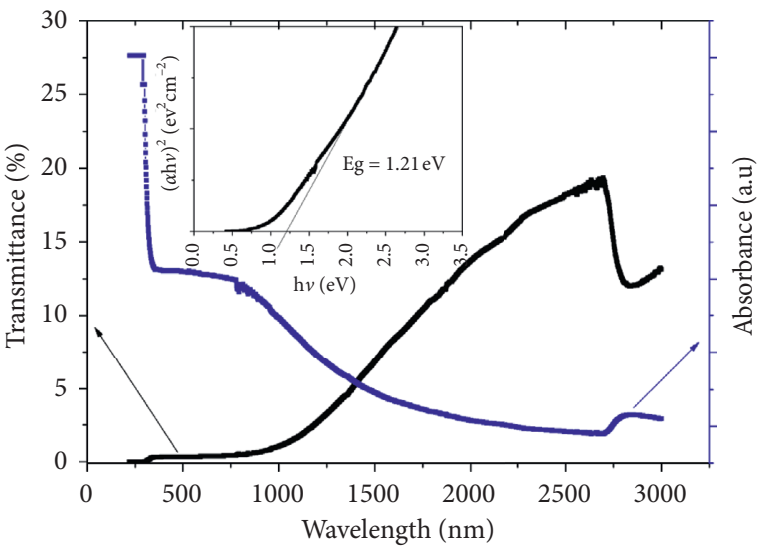

(b)

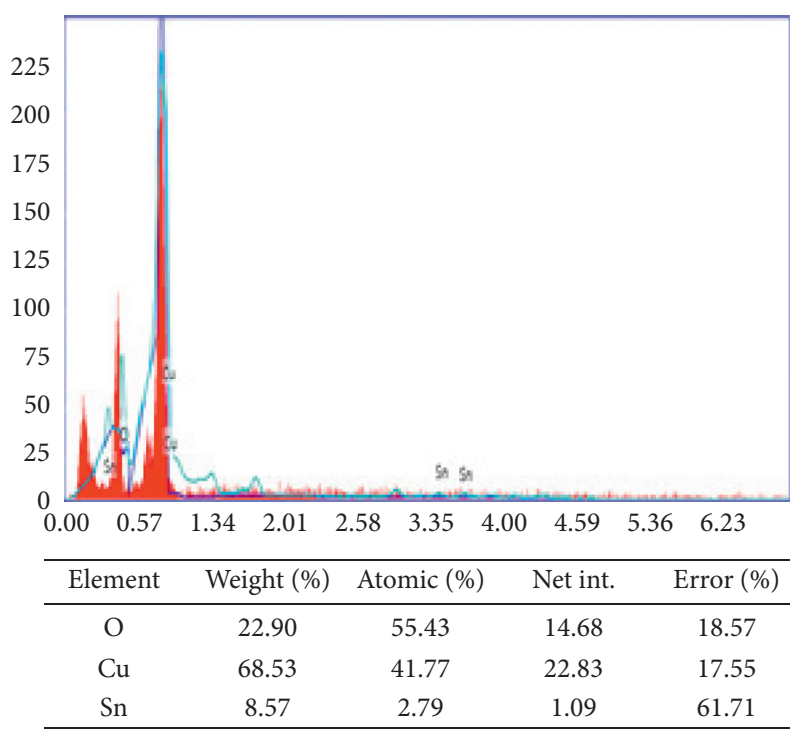

(d)

FIgURE 7: Data for the CuO NWs deposited on a thin copper film. (a) XRD patterns, (b) transmittance and absorbance data, (c) SEM images with a photo of a sample in the inset, and (d) EDX analysis for the sample obtained on the thin copper film.

$$
\alpha=\frac{\ln (1 / T)}{d}
$$

where $\alpha$ is the absorption coefficient, $T$ is the transmittance, and $\mathrm{d}$ is the film's thickness. The absorption was slightly better for the film, and prepared data are shown in
Figure 7(b). It is noted that the synthesized NWs exhibit a high absorbance, which indicates that the synthesized compound is a good candidate for solar cells and catalytic applications, and this high absorption is one of the properties that explain the interest in thin films in the field of photovoltaic conversion. 


\section{Conclusions}

For involvement in solar cells and catalytic activities applications, copper oxide NWs have been successfully synthesized by thermal oxidation of copper foils. Experimental data showed that the Vapor-Solid mechanism and the Vapor-Liquid-Solid mechanism are excluded, and the $\mathrm{CuO}$ nucleation was found to show a diffusion-controlled behavior. The formation of the $\mathrm{CuO}$ monoclinic phase leads to a pointed rhombic prism base for NWs nucleation.

Local bending is enhanced by thermal shock, which increases by increasing the heating rate and results in an increasing in the in-plane tensile stresses, which reduces the size of nucleation sites, and, hereby, enhances the NWs density. However, thick sites are needed to have rigid NWs and avoid their breaking. This study may have a broader impact for using recyclable metals in some technological devices.

As application, $\mathrm{CuO}$ NWs were successfully deposited on a copper thin film electrodeposited on an FTO/glass substrate. Structural and optical characterizations revealed that the thermal oxidation is a suitable way to obtain a large contact surface and, consequently, improve the efficiency of the device.

\section{Data Availability}

The characterization data and experimental results used to support the findings of this study are included within the article.

\section{Disclosure}

A part of this paper was used for participation in the Fifth International Symposium on Dielectric Materials and Applications ISyDMA'5 (see the link "https://www.isydma. com/poster-session-iii-2/").

\section{Conflicts of Interest}

The authors declare that there are no conflicts of interest regarding the publication of this paper.

\section{Authors' Contributions}

L. Nkhaili is the first author. He contributed to all experiments and a big part of the redaction. A. Narjis contributed to preparing samples, performing the SEM images, and in analysing the NWs growth mechanism. He contributed in all works of the paper. A. Agdad contributed to the discussion of a part of the X-ray Diffractions (DRX) patterns. He contributed to experimental detail and the results and discussion. A. Tchenka contributed to preparing samples and analysing optical data. A. El kissani contributed to preparing samples and analysing optical data. He contributed to experimental detail and the results and discussion. A. Outzourhit contributed to the improvement of the English of the manuscript. He supervised all our works, including this paper. A. Oueriagli helped to access the experiences and the necessary measurements. Also, he discussed the obtained results. He contributed to analysing and writing the paper.

\section{Acknowledgments}

The authors are grateful to Prof. Said Laasri from the National School of Applied Sciences of El jadida, Morocco, who helped to perform the XRD. A.N thanks Dr. Lahoucine Atourki from Ibn Zohr University, Morocco, for his help.

\section{References}

[1] M. Izaki, T. Shinagawa, K.-T. Mizuno, Y. Ida, M. Inaba, and A. Tasaka, "Electrochemically constructed $p-\mathrm{Cu}_{2} \mathrm{O} / n-\mathrm{ZnO}$ heterojunction diode for photovoltaic device," Journal of Physics D: Applied Physics, vol. 40, no. 11, p. 3326, 2007.

[2] S. Ishizuka, K. Suzuki, Y. Okamoto et al., "Polycrystalline n$\mathrm{ZnO} / p-\mathrm{Cu}_{2} \mathrm{O}$ heterojunctions grown by RF-magnetron sputtering," Physica Status Solidi (C), vol. 1, no. 4, p. 1067, 2004.

[3] J. Katayama, K. Ito, M. Matsuoka, and J. Tamaki, "Performance of $\mathrm{Cu}_{2} \mathrm{O} / \mathrm{ZnO}$ solar cell prepared by two-step electrodeposition," Journal of Applied Electrochemistry, vol. 34, no. 7, p. 687, 2004.

[4] N. D. Hoa, N. van Quy, H. Jung, D. Kim, H. Kim, and S.-K. Hong, "Synthesis of porous $\mathrm{CuO}$ nanowires and its application to hydrogen detection," Sensors and Actuators B: Chemical, vol. 146, no. 1, p. 266, 2010.

[5] D. Li, J. Hu, R. Wu, and J. G. Lu, "Conductometric chemical sensor based on individual CuO nanowires," Nanotechnology, vol. 21 , no. 48, p. 485502, 2010.

[6] Z. Chen, T. F. Jaramillo, T. G. Deutsch et al., “Accelerating materials development for photoelectrochemical hydrogen production: standards for methods, definitions, and reporting protocols," Journal of Materials Research, vol. 25, no. 1, p. 3, 2010.

[7] D. Mariotti and R. M. Sankaran, "Microplasmas for nanomaterials synthesis," Journal of Physics D: Applied Physics, vol. 43, no. 32, Article ID 323001, 2010.

[8] A. Angi, D. Sanli, C. Erkey, and O. Birer, "Catalytic activity of copper (II) oxide prepared via ultrasound assisted Fenton-like reaction," Ultrasonics Sonochemistry, vol. 21, p. 854, 2014.

[9] T. Ben-Moshe, I. Dror, and B. Berkowitz, "Oxidation of organic pollutants in aqueous solutions by nanosized copper oxide catalysts," Applied Catalysis B: Environmental, vol. 85, no. 3-4, pp. 207-211, 2009.

[10] X. Jiang, T. Herricks, and Y. Xia, "CuO nanowires can Be synthesized by heating copper substrates in air," Nano Letters, vol. 2, no. 12, p. 1333, 2002.

[11] C. H. Xu, C. H. Woo, and S. Q. Shi, "Formation of $\mathrm{CuO}$ nanowires on $\mathrm{Cu}$ foil," Chemical Physics Letters, vol. 399, no. 1-3, p. 62, 2004.

[12] J. T. Chen, F. Zhang, J. Wang et al., "CuO nanowires synthesized by thermal oxidation route," Journal of Alloys and Compounds, vol. 454, no. 1-2, p. 268, 2008.

[13] Y.-S. Kim, I.-S. Hwang, S.-J. Kim, C.-Y. Lee, and J.-H. Lee, "CuO nanowire gas sensors for air quality control in automotive cabin," Sensors and Actuators B: Chemical, vol. 135, no. 1, p. 298, 2008.

[14] W. Wang, Y. Zhan, and G. Wang, "One-step, solid-state reaction to the synthesis of copper oxide nanorods in the presence of a suitable surfactant," Chemical Communications, vol. 8, no. 8, pp. 727-728, 2001. 
[15] N. Mukherjee, A. Mondal, and U. Madhu, "Chemical bath deposition of thin films of $\mathrm{CuO}$ nanorods and their characterisation," International Journal of Nanomanufacturing, vol. 5 , no. $1 / 2$, p. $16,2010$.

[16] U. Cvelbar, K. Ostrikov, A. Drenik, and M. Mozetic, "Nanowire sensor response to reactive gas environment," Applied Physics Letters, vol. 92, no. 13, p. 133505, 2008.

[17] M. Meyyappan, "Catalyzed chemical vapor deposition of onedimensional nanostructures and their applications," Progress in Crystal Growth and Characterization of Materials, vol. 55, no. 1-2, p. 1, 2009.

[18] G. Filipic and U. Cvelbar, "Copper oxide nanowires: a review of growth," Nanootechnology, vol. 23, no. 19, p. 194001, 2012.

[19] Y.-H. Lee, I.-C. Leu, M.-T. Wu, J.-H. Yen, and K.-Z. Fung, "Fabrication of $\mathrm{Cu} / \mathrm{Cu}_{2} \mathrm{O}$ composite nanowire arrays on $\mathrm{Si}$ via AAO template-mediated electrodeposition," Journal of Alloys and Compounds, vol. 427, no. 1-2, p. 213, 2007.

[20] B. S. Khan, A. Saeed, S. S. Hayat, A. Mukhtar, and T. Mehmood, "Mechanism for the formation of cuprous oxide nanowires in AAO template by electrodeposition," International Journal of Electrochemical Science, vol. 12, pp. 890-897, 2017.

[21] W. Wang, Y. Zhuang, and L. Li, "Structure and size effect of $\mathrm{CuO}$ nanowires prepared by low temperature solid-phase process," Materials Letters, vol. 62, no. 10-11, p. 1724, 2008.

[22] W. Z. Wang, G. H. Wang, X. S. Wang, Y. J. Zhan, Y. K. Liu, and C. L. Zheng, "Synthesis and characterization of $\mathrm{Cu}_{2} \mathrm{O}$ nanowires by a novel reduction route," Advanced Materials, vol. 14, no. 1, p. $67,2002$.

[23] G. Arnoult, R. P. Cardoso, T. Belmonte, and G. Henrion, "Flow transition in a small scale microwave plasma jet at atmospheric pressure," Applied Physics Letters, vol. 93, no. 19, p. 191507, 2008.

[24] V. Kumar, J. H. Kim, J. B. Jasinski, E. L. Clark, and M. K. Sunkara, "Alkali-assisted, atmospheric plasma production of titania nanowire powders and arrays," Crystal Growth \& Design, vol. 11, no. 7, p. 2913, 2011.

[25] S. Wang, Q. Huang, X. Wen, X.-y. Li, and S. Yang, "Thermal oxidation of $\mathrm{Cu}_{2} \mathrm{~S}$ nanowires: a template method for the fabrication of mesoscopic $\mathrm{Cu}_{x} \mathrm{O}(x=1,2)$ wires," Physical Chemistry Chemical Physics, vol. 4, no. 14, p. 3425, 2002.

[26] C.-T. Hsieh, J.-M. Chen, H.-H. Lin, and H.-C. Shih, "Synthesis of well-ordered $\mathrm{CuO}$ nanofibers by a self-catalytic growth mechanism," Applied Physics Letters, vol. 82, no. 19, p. 3316, 2003.

[27] J. Liang, N. Kishi, T. Soga, and T. Jimbo, "Cross-sectional characterization of cupric oxide nanowires grown by thermal oxidation of copper foils," Applied Surface Science, vol. 257, no. 1, pp. 62-66, 2010.

[28] A. M. B. Goncalves, L. C. Campos, A. S. Ferlauto, and R. G. Lacerda, "On the growth and electrical characterization of $\mathrm{CuO}$ nanowires by thermal oxidation," Journal of Applied Physics, vol. 106, Article ID 034303, 2009.

[29] R. S. Wagner and W. C. Ellis, "Vapor-liquid-solid mechanism of single crystal growth," Applied Physics Letters, vol. 4, no. 5, p. $89,1964$.

[30] S. S. Brenner and G. W. Sears, "Mechanism of whisker growth-III nature of growth sites," Acta Metallurgica, vol. 4, no. 3, p. 268, 1956.

[31] E. Mack, G. G. Osterhof, and H. M. Kraner, "Vapor pressure of copper oxide and of copper," Journal of the American Chemical Society, vol. 45, p. 617, 1923.

[32] H. Busch, A. Fink, A. Muller, and K. Samwer, "Occurrence and origin of copper oxide particulates prior to the deposition of $\mathrm{YBaCuO}$ thin films," Superconductor Science and Technology, vol. 5, no. 11, p. 624, 1992.

[33] L. Yuan, Y. Wang, R. Mema, and G. Zhou, "Driving force and growth mechanism for spontaneous oxide nanowire formation during the thermal oxidation of metals," Acta Materialia, vol. 59, no. 6, p. 2491, 2011.

[34] M. Chen, Y. Yue, and Y. Ju, "Growth of metal and metal oxide nanowires driven by the stress-induced migration," Journal of Applied Physics, vol. 111, no. 10, p. 104305, 2012.

[35] A. Li, H. Song, J. Zhou, X. Chen, and S. Liu, "CuO nanowire growth on $\mathrm{Cu}_{2} \mathrm{O}$ by in situ thermal oxidation in air," CrystEngComm, vol. 15, no. 42, p. 8559, 2013.

[36] S. Q. Zhao, Crystallography and Mineralogy, Higher Education Press, Beijing, China, 2005.

[37] G. Zhou, "Nucleation thermodynamics of oxide during metal oxidation," Applied Physics Letters, vol. 94, no. 20, p. 201905, 2009.

[38] R. Mema, L. Yuan, Q. Du, Y. Wang, and G. Zhou, "Effect of surface stresses on $\mathrm{CuO}$ nanowire growth in the thermal oxidation of copper," Chemical Physics Letters, vol. 512, no. 1-3, pp. 87-91, 2011. 